7 - ORIGINAL ARTICLE

WOUND HEALING

\title{
Expression of P53, HER2 and Ki67 proteins in rats subjected to bladder augmentation with stomach, colon and ileum ${ }^{1}$
}

\author{
Edinaldo Gonçalves de Miranda ${ }^{\text {I }}$, Celina Teresa Castelo Branco Couto de Miranda ${ }^{\text {II }}$, Antônio Igor Paraiba Lopes ${ }^{\text {III }}$, Diógenes \\ Miranda Santana ${ }^{\text {III }}$, João Emílio Pinheiro Lemos Filho ${ }^{\text {III, }}$ Thiago Pereira Diniz ${ }^{\text {III }}$, José Figueredo Silva ${ }^{\text {IV }}$, Jaques Waisberg ${ }^{\mathrm{V}}$
}

DOI: http://dx.doi.org/10.1590/S0102-865020160010000007

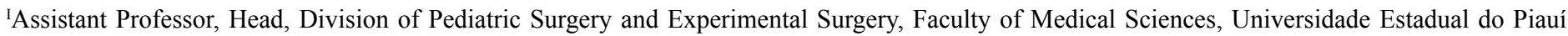
(FACIME/UESPI), Brazil. Intellectual, scientific, conception and design of the study; acquisition and interpretation of data; technical procedures; statistical analysis; manuscript preparation and writing.

IIAssistant Professor, Head, Division of Nephrology, FACIME/UESPI, Teresina-PI, Brazil. Manuscript preparation and writing, critical revision.

III Graduate student, FACIME/UESPI, Teresina-PI, Brazil. Acquisition of data.

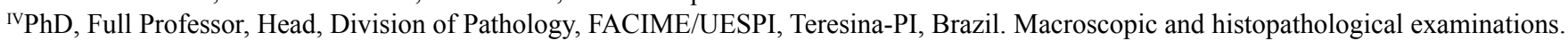

${ }^{\mathrm{v}} \mathrm{PhD}$, Associate Professor, Faculty of Medicine of ABC, Department of Surgery, Hospital do Servidor Público Estadual, Sao Paulo-SP, Brazil. Intellectual, scientific, conception and design of the study; critical revision, final approved.

\section{ABSTRACT \\ PURPOSE: To study the expression of HER2, p53 and Ki67 proteins in cystoplasties.}

METHODS: Sixty rats were distributed randomly into three groups of 20 animals. Bladder augmentation was held to increase with ileum (Group I), colon (Group II) and stomach (Group III). Tissue samples of neobladder was collected from each rat to its own control. The animals were sacrificed after 12 weeks. The neobladder was withdrawn for immunohistochemitry analysis of p53, HER2 and Ki67 expression. Wilcoxon and Mann-Whitney tests were used for statistical study.

RESULTS: There were no significant changes in the expression of p53 and HER2 proteins. It was observed significant increase $(p<0.0001)$ in Ki67 expression in all groups, when compared with their respective controls. When the study groups were compared with each other, there was increase of cell proliferation in the largest gastrocystoplasties in respect of ileocystoplasties $(\mathrm{p}=0.004)$ and colocystoplasties $(\mathrm{p}=0.003)$.

CONCLUSION: We observed significant increase of cell proliferation characterized by Ki67 protein in the digestive tract of the ileocystoplasties, the colocystoplasties and the gastrocystoplasties and this increase was significantly greater in gastrocystoplasties.

Key words: Urinary Bladder. Neoplasms. Genes, p53. Rats. 


\section{Introduction}

Several diseases affect the lower urinary tract and require the use of digestive tract into the urinary derivation to partial or total replacement of the bladder to preserve renal function and reestablish the excretory urinary function ${ }^{1}$. The first therapeutic measure for these patients is pharmacological ${ }^{2}$ therapy, surgical treatment for no responsive cases, for patients with congenital disorders and for those that have undergone the operation that resulted in anatomical or functional impairment of the lower urinary tract.

The operation to be performed must be individualized for each patient, always with the objective to increase bladder capacity with low pressure, obtain effective ureteral anti-reflux mechanism and offer the adequate urinary continence ${ }^{2}$. Different tissues and biological materials have been used to find the ideal element to increase bladder capacity. The ileum was and continues to be the most used ${ }^{3}$, but it is also used colon, stomach, mucolized or demucolized, ureter, myoperitoneal patchwork, placenta, dura omentum, bovine pericardium, bladder auto enlargement techniques, such as detrusorectomies, botulinum toxin application and genetic engineering techniques with homologous and heterologous tissues, as well as bladder transplant and synthetic bladder were also described ${ }^{4-6}$.

Each of these techniques has advantages and disadvantages and its use should be individualized, because complications may occur such as metabolic disorders, mucoid discharge, visceral pain distension, spontaneous perforation, calculations and urinary infections, hemorrhagic cystitis, complications with ventriculoperitoneal shunt, vesico-ureteral reflux, urinary loss, intestinal disorders, reproductive alterations in female and tumors development ${ }^{7}$.

Although the association of cancer and bladder augmentation is well documented ${ }^{8}$, the carcinogenesis is not yet completely understood. It is known, however, that histological changes predate neoplasms occurrence in the intestinal mucosa, characterized initially by submucosal edema, submucosal cell hyperplasia, acute and chronic inflammatory process, swelling, distortion and hypercellularity crypts, tissue atrophy metaplasia, dysplasia, changes in intestinal mucins and molecular changes in the expression of oncogenes, being cited among them the p53, HER2 and ki67, being present in the gastrointestinal and urinary tract neoplasms like most recently in neoplasms in cystoplasties augmentation $^{9,10}$.

Given these controversies, the objective of this study was to analyze in Wistar rats submitted to cystoplasties with ileum, colon and stomach, any early changes in the expression of P53, HER2 and Ki67 proteins in intestinal segment of neobladder, since it's well established the role of these proteins in human carcinogenesis, either by changes in cell proliferation, in regulating the cell cycle or in the evolution of neoplasm, directly influencing both the appearance of neoplasms, like its gravity and evolution.

\section{Methods}

After approval by Ethics Committee of Animals use in Research of Universidade Federal de São Paulo, with number 656896, 60 rats Wistar (Rattus norvegicus), aged between 150 and 180 days (average of 167 days) and weight of $220 \mathrm{~g}$ to $350 \mathrm{~g}$ (average of $283.5 \mathrm{~g}$ ) were distributed into three groups with 20 animals, by random drawing and submitted to cystoplasty: ileocystoplasty (Group I), colocystoplasty (Group II) and gastrocystoplasty (Group III). The animals were kept in collective cages before the surgery and in individual cages after the procedure, received free balanced feed and water and were kept at ambient temperature and light in the pre and postoperatively. The rats were anesthetized with sevoflurane and subjected to longitudinal median incision for laparotomy. The digestive tract was pulled with atraumatic forceps until expose bowel segment to be used: ileum, colon or stomach (Figure $1 \mathrm{~A}, \mathrm{C}, \mathrm{E}$ ).

For the end-terminal intestinal anastomosis (Group I and group II) and the gastric suture (Group III) were used 6.0 polyglactin wires with cylindrical needle, with separate points in single plan.

We proceeded to the exposure of the bladder to the bladder dome resection and realization of bladder augmentation with the segment of the digestive tract that corresponds to each group. After the procedure, the abdominal wall was closed by planes.

\section{Surgical technique used on cystoplasty augmenta- tion}

Group I - ileocystoplasty with ileal flap ${ }^{11}$. Isolated segment of $3 \mathrm{~cm}$ flap of ileum, distant $10 \mathrm{~cm}$ of cecum. Of this ileal segment, retired $1 \mathrm{~cm}$ from proximal end to histological control of each animal (GIe). Then, the partial cystectomy, withdrawing $1.0 \mathrm{~cm}$ from the bladder dome. Terminal ileal pedicellate segment , isoperistaltic sense, was then incorporated into the remaining bladder and the proximal end sutured to the neobladder lock (Figure 1B).

Group II - Colocystoplasty with colon flap ${ }^{12}$. Isolated 
segment of $3 \mathrm{~cm}$ neck flap, $15 \mathrm{~cm}$ approximately of pelvic peritoneal reflection. Of this segment was removed $1 \mathrm{~cm}$ from colon proximal to histological control of each animal (GIIe). The other times were carried out with the same surgical technique employed in Group I (Figure 1D).

Group III - Gastrocystoplasty, with tissue flap ${ }^{12}$. It was removed gastric body segment, lozenge-shaped, measuring $1 \mathrm{~cm}$ in each of its four sides, while preserving the left gastroepiploic artery, vascularization with vascular graft pedicle obtained connecting the branches of the artery that irrigates the proximal and distal gastric portions of the graft. Then, took the graft to the bladder, whose dome was parched, and proceeded to the anastomosis with simple points, separated, involving the entire wall. The gastric suture was performed with simple points, separated and single plan (Figure 1F). At this time it was collected the gastric tissue measuring $1 \mathrm{~cm}$ to histological control of each animal (GIII)).The material collected for control of the three groups was washed with hydrosaline solution to $0.9 \%$ and fixed immediately in $10 \%$ formalin. After 12 weeks, the animals were sacrificed with sevoflurane and autopsied (Figure 2).

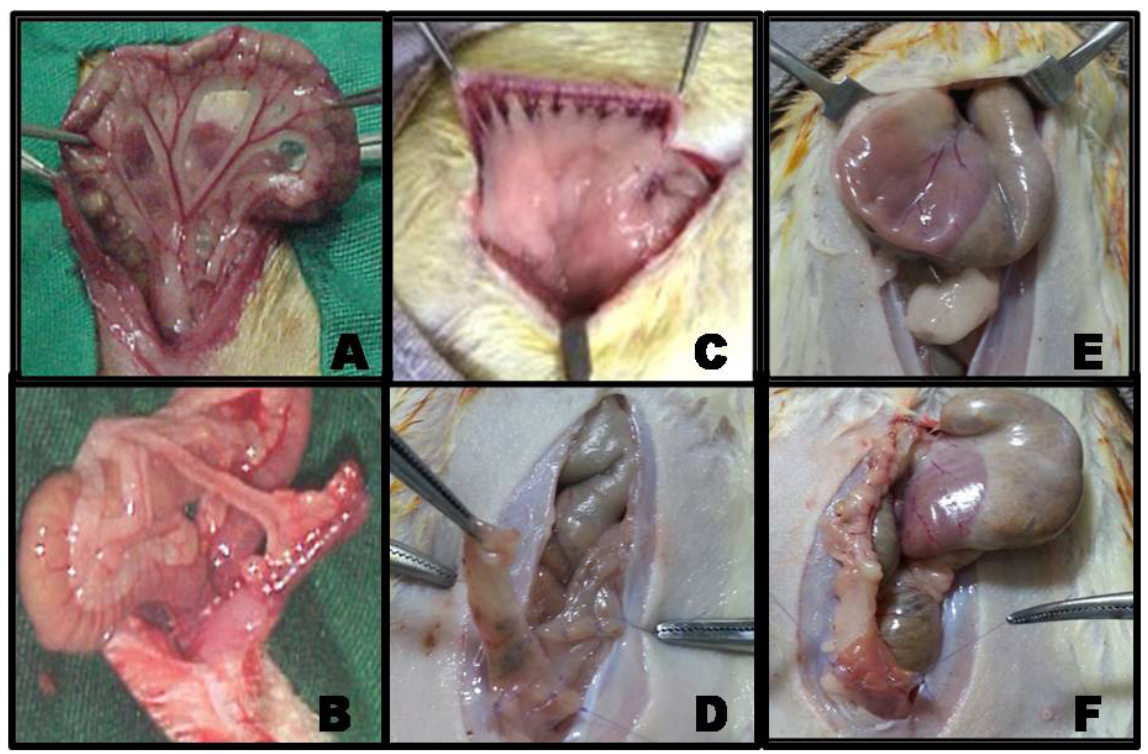

FIGURE 1 - A) Exhibition of ileal segment used in ileocystoplasties; B) Ileocystoplasty; C) Exhibition of colon segment used in colocystoplasties; D) Colocystoplasty; E) Exhibition of gastric used in gastrocystoplasties; F) Gastrocystoplasty.

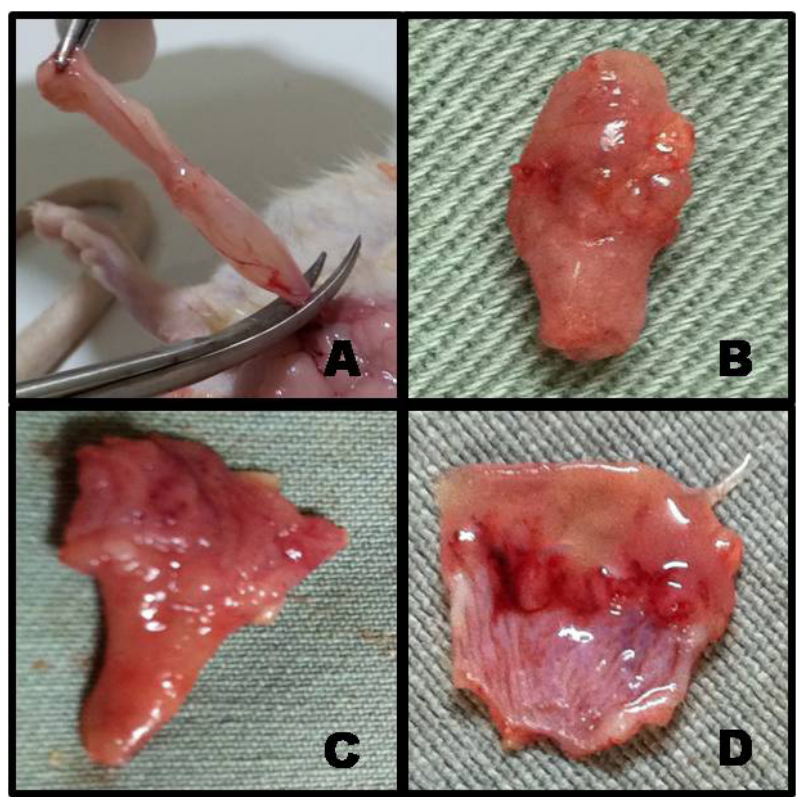

FIGURE 2 - Collection of sample cystoplasties augmentation to immunohistochemistry. A) Ileocystoplasty; B) Colocystoplasty; C) Gastrocystoplasty; D) Neobladder opening.
The neobladder was collected, open the washed with hydrosaline solution $0.9 \%$, fixed in $10 \%$ formalin and included in paraffin according to routine technique. It obtained 4 serials thickness for immunohistochemical study and evaluation of expression of ki67 p53, and Her2 proteins. The analysis of the immunohistochemical expression of these proteins was performed by two experienced and independent pathologists.

The immunohistochemical study was performed by the evaluation of computerized images. This assessment was done for accurate and automatic delineation of immunomarked areas and conversion of RGB images (24-bit), obtained of stained blades with hematoxylin in 8-bit images normalized for the blue channel. For the calculation, each RGB image was first duplicated and separated into three separate images to grayscale (8-bit), leading channel information of red, green and blue colors, respectively. A new image (BN) of 8-bit was designed to receive, pixel for pixel, the values obtained from the computerized calculation on 
the values contained in each pixel of the images of the three color channels. R, G and B are the values of the pixels of the three color channels red (red), green (green) and blue (blue), respectively ${ }^{13}$.

The images were captured with bright field microscopy and $40 \mathrm{X}$ lens through trinolucular microscope (Olympus CX31 YS100 model, Inc., Tokyo, Japan) equipped with digital camera (Moticam WiFi X, MoticMicroscopes, Richmond, VA, USA) coupled to a computer. In neobladder from each animal were captured images of five distinct areas (controls) and neobladder mucosa of the stomach, small intestine and colon. The images generated were recorded in RGB (24-bit) Tiff format, uncompressed, and possessed the size of $1280 \times 1024$ pixels. The processing and analyzing of the images were taken with the public domain software ImageJ 1.43, 64-bit version (National Institutes of Health, Bethesda, MD, USA). The programmed code in macro commands to generate the normalized image $\mathrm{BN}^{13}$

Statistical analysis between the groups was performed using non-parametric tests of Wilcoxon and Mann-Whitney. Settled at $5 \%(p<0.05)$ the level of rejection of the hypothesis of invalidity.

\section{Results}

The presence of changes in $\mathrm{Ki} 67$ protein expression was detected in tissue samples of ileum of control grups like in the ileociystoplasty group, (Ic), in the of colocystoplasties (Group IIc) and gastric segment of gastrocystoplasties (Group IIIi) (Figure 3), but without significance when compared with each other: Ic $\mathrm{x}$ IIc $(\mathrm{p}=0.3425)$, Ic $x$ IIIc $(\mathrm{p}=0.2538)$ and IIc $x$ IIIc $(\mathrm{p}=0.1337)$.

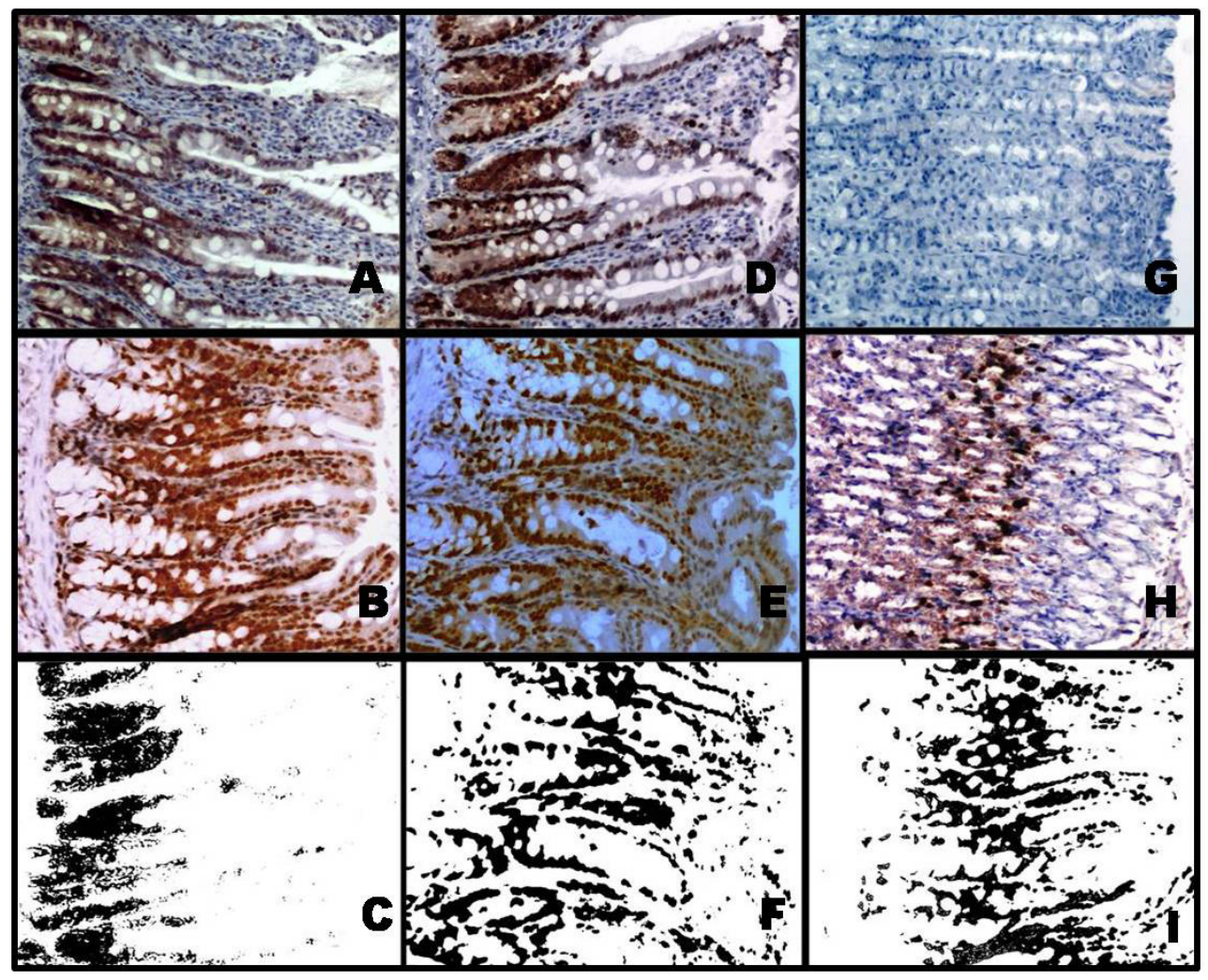

FIGURE 3 - Immunohistochemistry study to Ki-67 showing positive coloring of epithelial cell in several segments. A) Native ileal mucosa; B) Ileocystoplasty; C) Ileocystoplasty image normalized by blue (BN) applying the comand "threshold", of positive area of 12.3\%; D) Native colonic mucose; E) Colocystoplasty; F) Colocystoplasty image with positive area of $16.5 \%$; G) Native gastric mucosa; H) Gastrocystoplasty; I) Gastrocystoplasty image with positive area of $25.5 \%$. J) Increase of x 100 .

It was observed significant increase in $\mathrm{Ki67}$ protein expression in all groups, as compared with their respective control: Group I ( $<<0.001)$; Group II ( $\mathrm{p}<0.0001)$; Group III ( $\mathrm{p}<$
0.0001) (Table 1). There was no significant difference between the study groups Ie ( ileocystoplasty) and IIe ( colocystoplasty) $(\mathrm{p}=0.5983)$. 
TABLE 1 - Review of Ki-67 in tissue samples of controls intestine of ileocystoplasty (group Ic), of control intestine of colocystoplasties (group IIc) and of control segment of gastrocystoplasties (group IIIc).

\begin{tabular}{|c|c|c|c|}
\hline $\mathrm{N}^{\mathrm{o}} \mathrm{RAT}$ & $\begin{aligned} \text { GROUP } & \text { Ic } \\
(\%) & \end{aligned}$ & $\begin{array}{c}\text { GROUP IIc } \\
(\%)\end{array}$ & $\begin{array}{c}\text { GROUP IIIc } \\
(\%)\end{array}$ \\
\hline 1 & 8.5 & 8.2 & 6.2 \\
\hline 2 & 8.1 & 7.8 & 7.8 \\
\hline 3 & 4.7 & 7.9 & 8.1 \\
\hline 4 & 6.3 & 5.6 & 6.3 \\
\hline 5 & 5.7 & 6.1 & 8.3 \\
\hline 6 & 8.2 & 8.5 & 7.5 \\
\hline 7 & 6.4 & 6.3 & 6.8 \\
\hline 8 & 8.1 & 7.8 & 4.8 \\
\hline 9 & 7.0 & 8.2 & 6.3 \\
\hline 10 & 6.5 & 5.5 & 6.8 \\
\hline 11 & 7.1 & 7.4 & 6.2 \\
\hline 12 & 6.1 & 6.6 & 8.3 \\
\hline 13 & 5.9 & 5.0 & 5.4 \\
\hline 14 & 7.3 & 8.0 & 8.6 \\
\hline 15 & 8.5 & 6.6 & 8.5 \\
\hline 16 & 3.0 & 4.7 & 1.9 \\
\hline 17 & 2.6 & 2.0 & 7.1 \\
\hline 18 & 8.0 & 4.9 & 7.4 \\
\hline 19 & 5.1 & 4.2 & 5.3 \\
\hline 20 & 6.0 & 6.6 & 8.3 \\
\hline MÉDIAS & 6.4 & 6,4 & 6.7 \\
\hline
\end{tabular}

$\%$ of marked area, Ic x IIc ( $\mathrm{p}=0.3425)$, Ic x IIIc $(\mathrm{p}=0.2538)$, IIc $\mathrm{x}$ IIIc $(p=0.1337)$.

When the study group IIIe ( gastrocystoplasty) was compared with groups Ie and IIe showed a statistically significant difference $(\mathrm{p}=0.0199$ and $\mathrm{p}=0.0086)$, respectively (Table 2$)$.
TABLE 2 - Genic expression of Ki-67 in intestine mucosa of ileocystoplasies, (G Ie), in the intestine of colocystoplasties ( $G$ $\mathrm{IIe}$ ) and in the gastric segment of gastrocystoplasties (G IIIe).

\begin{tabular}{|c|c|c|c|c|}
\hline $\mathrm{N}^{\mathrm{o}} \mathrm{RAT}$ & $\begin{aligned} \text { GROUP } & \text { Ie } \\
(\%) & \end{aligned}$ & $\begin{array}{r}\text { GROUP } \\
(\%)\end{array}$ & IIe & $\begin{array}{c}\text { GROUP } \\
(\%)\end{array}$ \\
\hline 1 & 27 & 26 & & 30 \\
\hline 2 & 20 & 28 & & 29 \\
\hline 3 & 27 & 21 & & 30 \\
\hline 4 & 35 & 32 & & 21 \\
\hline 5 & 27 & 26 & & 19 \\
\hline 6 & 26 & 22 & & 23 \\
\hline 7 & 15 & 15 & & 39 \\
\hline 8 & 19 & 19 & & 42 \\
\hline 9 & 19 & 18 & & 32 \\
\hline 10 & 19 & 15 & & 31 \\
\hline 11 & 17 & 17 & & 22 \\
\hline 12 & 15 & 18 & & 21 \\
\hline 13 & 17 & 19 & & 20 \\
\hline 14 & 15 & 16 & & 20 \\
\hline 15 & 18 & 15 & & 18 \\
\hline 16 & 11 & 13 & & 19 \\
\hline 17 & 11 & 12 & & 18 \\
\hline 18 & 11 & 14 & & 17 \\
\hline 19 & 12 & 13 & & 16 \\
\hline 20 & 14 & 10 & & 17 \\
\hline MÉDIAS & 18 & 18 & & 24 \\
\hline
\end{tabular}

$\%$ of marked area, Ie $x$ IIe $(\mathrm{p}=0.4730)$, Ie $x$ IIIe $(\mathrm{p}=0.0043)$, IIe $\mathrm{x}$ IIIe $(\mathrm{p}=0.0034)$.

\section{Discussion}

The development of benign or malignant neoplasms in the intestinal mucosa due to contact with the urine has been described since 1980. Between the benign neoplasms, the most frequent histological type is the adenomatous polyp that is represented by tubulovilosos, transitional cell adenomas or mixed. It is known that adenomas larger than $1.5 \mathrm{~cm}$ have above $70 \%$ risk 
of malignat transformation and the risk is greater in the highest latency time and in the youngest sicks $^{14}$.

The carcinogenesis can be triggered by prolonged contact between urine and the mucosa of the intestinal segment used to urinary tract reconstruction ${ }^{15}$. That seems to be strengthened by, no case of cancer has been documented in patients underwent bladder augmentation with demucolized bowel or in patients undergoing ureterocystoplasty ${ }^{15}$. Possibly, the carcinogenesis in intestinal segments incorporated into the urinary tract has a multifactorial origin and different endogenous and exogenous agents act as initiators that cause irreversible changes in the DNA structure and create the conditions for the action of promoters agents of neoplastic process ${ }^{14,16}$.

It was suggested the triggering participation in neoplastic conversion process of nitrosamines derived from the activation of nitrosamidas, through mutagenic effect. This activation results in the presence of chronic infections, found both in patients with ileal conduits, colonic and bladder augementations, as in atrophic gastric mucosa, which is related to appearance of gastric neoplasms, especially adenocarcinomas, which is the most frequent histological type of malignant neoplasms found in patients undergoing gastrocystoplasties ${ }^{16}$.

Other factors such as the lack of fatty acid, the surgical trauma, the presence of the suture thread, changes in the concentration of lecithin and ornithine decarboxylase in line of suture and increasing fibroblast growth factor has also been implicated in neoplastic conversion process ${ }^{17}$.

Changes in the concentrations of sialomucinas and sulfomucinas in urointestinal suture line and intestine flap of neobladder were considered as contributing factors to the emergence of neoplasms ${ }^{17},{ }^{18}$. However, the clinical applicability of research methods of sialomucinas and sulfomucinas is difficult, which limits its clinical use in large scale.

Due the controversies in the etiology of carcinogenesis there is the need to study the early changes in the urinary tract reconstruction that may be considered premalignant and that could be detected by method of easy clinical applicability. Studies related changes in gene expression of p53 and ki67 in patients who have tumors after undergoing bladder augmentation and it has been suggested that this occurs by the fact of increased cystoplasties create a surgical environment that leads to gene instability and encourages the emergence of triggering changes of neoplasms ${ }^{18,19}$. In this study, in experimental model analogue that performed clinically on humans, without the presence of feces, sought to evaluate the expression of Ki67, p53 and HER2 proteins which are related to digestive and urinary tract tumors studied until the moment. The time of observation was of 12 weeks because it corresponds to eight years in humans, sufficient time to install any areas with tissue neoplasms of digestive tract in cystoplasty increase $^{20}$.

The duration of the experiment was established on the basis of experimental works ${ }^{20}$, where it was estimated that eight weeks in Sprague-Dawley rats submitted to urinary derivation would lead to five years in humans. Recent works have recorded cases of cancer between two and five years after the surgical procedure $^{15}$. It is expected, therefore, that the onset of neoplasms in rats occur in periods as short as four to eight weeks. Thus, the time of 12 weeks was considered suitable for studying possible changes that occurred before the early emergence of malignant neoplasms.

Inhalation anesthesia with isoflurane was preferred in relation to other modalities for allowing more appropriate control anesthetic of the phases of anesthetic induction, maintenance and recovery while avoiding losses of animals and other complications related to this procedure when performed with different techniques and drugs ${ }^{21}$.

The calculation of the number of animals was conducted considering the level of confidence of $95 \%$, based on the fact that the literature estimates maximum percentage of occurrence of neoplasm in patients undergoing cistoplasty and which does not exceed $15 \%$, that take it beyond the incidence of digestive and urinary tract cancer in the general population. It was considered, still, sampling error of $10 \%$, that for the purpose of calculating the amount of the sample is defined by the researcher and should not extrapolate twice the estimated incidence that is $5 \%$. It was considered the significant value of $p<0.05$ and using the online calculator which uses the population, normal standardized variable associated with the level of confidence, the real probability of the event and the sampling error. Thus, the sample amount of 19 animals for each group and that plus $5 \%$ of estimated animals losses, the number of animals of each group was defined in 20 animals.

Among the existing techniques for investigation of expression of p53, the Immunohistochemistry is the most used and the main reasons for your job is your convenience and availability in virtually all pathology laboratories. Can be made by biopsy or surgical specimens processed and included in paraffin blocks conventionally. 
The quantification of the immunolabeling parameters on image analysis of Immunohistochemistry depends on the delimitation of the marked regions in relation to no marked ${ }^{22}$. The selection of the regions identified as marked positively can be done manually by direct marking on each image. However this method of selection is subject to variations of the observer and the difficulties of selection when low levels of antigens are stained on a dark against coloring.

How computational methods have been developed to carry out rapid separation of immunostained areas of background images, automatically or semi-automatically, decreasing considerably the operator intervention and $v^{2}{ }^{23}$. We opted for the ImageJ software to be well set to computerized program of easy handling, available in the public domain and use the automatic selection of areas marked by immunohistochemistry ${ }^{23}$.

Present in most Neoplasms of the digestive tract and urinary tract, p53, HER2 and Ki67 genes has been studied in isolation in case reports of emergence of neoplasms in cystoplasties and it has been suggested the need for studies to determine their true role in carcinogenesis in these environments considered the areas of permanent genetic instability ${ }^{11,12}$.

In cystoplasties, the study of the gene p53 is important, because it has increased expression of his mutant variant in 50 to $70 \%$ of neoplasms in the urinary tract, such as transitional cell carcinoma of bladder, and in $60 \%$ to $80 \%$ of colorectal and gastric tumors, beyond the presence in the chronic inflammatory process. Observed changes in the expression of $\mathrm{p} 53$ protein in patients underwent bladder augmentation, which suggests that these patients should undergo evaluation of gene expression at the time of intestinal reconstruction to determine possible risk group and conducting periodic biopsies to study the immunoexpression of proteins expressed by this genes.

The HER2 is a proto-oncogene that encodes a transmembrane receptor of tyrosine growth factor and has a regulatory role in cells with normal operation. A random error in this gene can lead to overexpression and development of cancer, though this change present in many types of solid tumors. Initially considered an event early and stable in the genesis of breast cancer, HER2 has been increasingly implicated in carcinogenesis of gastrointestinal and Urologic tumors, particularly in the gastric carcinoma.

In the present study, however, no increase was observed in the expression of the proteins expressed by p53 and HER 2 genes in intestinal mucosa of control groups and intestinal segment of gastrocystoplasties, ileocystoplasty and colocystoplasty, event that may have occurred by the time of 12 weeks, while the human cases reported in the literature had latency period exceeding 10 years $^{24}$.

The Ki67 gene has been linked to chronic inflammatory process, the colorectal adenocarcinoma and vesical neoplasms. A single experimental study on 35 rats divided into three groups and submitted to ileocystoplasties, colocystoplasties and gastrocystoplasties studied p53, HER2, Ki67 and MUC genes and showed that the vesical expansions in mice lead to instability of these genes and possibly may increase the risk of emergence of neoplasms.

In the present study found increased activity of Ki67 in control groups in less than $10 \%$ of the cells, which is considered normal $^{9,24}$. On the other hand, the study groups also noted the presence of Ki67 activity in value greater than 10\%, showing significant increase of proliferation and cellular activity in these animals underwent bladder augmentation with ileum, colon or stomach.

When were compared, the study groups ileocystoplasty and colocystoplasty showed no significant difference in relation to the presence of cell proliferation among these groups. However, when they were compared with the group that used the gastric segment for bladder augmentation it was found that there was significant increase in gastric group compared to previous, showing cellular proliferative activity more intense.

The results in the immunoexpression of Ki67 protein showed that the increased cell proliferation activity can lead a higher probability of occurring changes in gene expression of p53 and HER2 genes, which leads to need for further studies with a larger time of observation ${ }^{25}$.

The significant increase of cell proliferation in gastrocystoplasties in relation to the groups which were used colon and ileum confirm the findings described that show greater gene instability in these patients ${ }^{26}$. The changes found strengthen the studies that suggest that these kind of surgical procedures create favorable environment to gene instability, probably by the presence of chronic inflammatory process. Some authors have suggested that the chronic inflammatory process resulting from the constant presence of urine or other carcinogens can cause reaction in the tissue stroma with intense infiltration of monocytic cells and with other changes, like the increase of the core/cytoplasm relationship of Goblet cells and the release of free radicals of oxygen able to influence the cellular transformation 
acting on the DNA strand, which would influence the process of carcinogenesis promotions ${ }^{4,27}$. While surgical alternatives such as tissue engineering, bladder transplant or even artificial bladder are not available and intestinal segments are used routinely to the urinary tract reconstruction, studies of expression of genes and their proteins related to neoplasm should be encouraged, because the importance of characterizing premalignant lesions is unquestioned and will contribute to a better quality of life and survival of patients who require the achievement of cystoplasties.

\section{Conclusions}

Under the conditions of this experiment, was not observed alteration in p53 and HER expression in the ileocystoplasties, colocystoplasties and gastrocystoplasties. Showed significant increase in $\mathrm{Ki} 67$ protein expression in three groups of animals subjected to cystoplasty, being greater in those submitted to gastrocystoplasties.

\section{References}

1. Baskin LS, Hayward SW, Di Sandro MS, Li YW, Cunha GR. Epithelial-mesenchymal interactions in the bladder. Implications for bladder augmentation. Urol Clin North Am. 1999;26:49-59. PMID: 10599413.

2. Game X; Karsenty G; Chartier-Kastler E; Ruffion A. Treatment of neurogenic detrusor hyperactivity: enterocystoplasty. Prog Urol. 2007;17(3):584-96. PMID: 17622095.

3. Djordjevic ML, Vukadinovic V, Stojanovic B, Bizic M, Radojicic Z, djordjevic D; Krstic Z. Objective long-term avaluation after bladder autoaugmentation with rectus muscle backing. J Urol. 2015;193(5 suppl):1824-9. PMID: 25817151.

4. Lam van $\mathrm{Ba} \mathrm{O}$, Aharony $\mathrm{S}$, Loutochin $\mathrm{O}$, Corcos J. Bladder tissue engineering: a literature review. Adv drung Deliv Rev. 2015;8283:31-7. PMID: 25446136 .

5. Serhat G, Jody N, Iyimser U, Robert PE De Gier, Mustafa OT, Wouter F. Bladder augmentation: review of the literature and recent advances. Indian J Urol. 2007;23(4):452-7. doi: 10.4103/09701591.36721

6. Gurocak S, Nuininga J, Ure I, De Gier RP, Tan MO, Feitz W. Bladder augmentation: review of the literature and recent advances. Indian $\mathrm{J}$ Urol. 2007;23(4):452-7. PMID: 19718303.

7. Rink R. Bladder augmentation, options, outcomes, future. Urol Clin North Am. 1999;26(1):111-23. PMID: 10086054.

8. Husmann DA. Malignacy after gastrointestinal augmentation in childhood. Ther Adv Urol. 2009;1(1):5-11. doi: $10.1177 / 1756287209104163$.

9. Ivil KD, Jenkins SA, Doak SH, Hawizy AM, Kynaston HG, Parry EM, Jenkins GJ, Parry JM, Stephenson TP. Identification or early p53 mutations in clam ileocystoplasties using restriction site mutation assay. Urology. 2007;70(5):905-9. PMID: 17919692.

10. Sung MT, Zhang S, Lopez-Beltran A, Montironi R, Wang M, Davidson DD, Koch MO, Cain MP, Rink RC, Cheng L. Urothelial carcinoma following augmentation cystoplasty: an aggressive variant with distinct clinical pathological characteristics and molecular genetic alterations. Histopathology. 2009;55(2):161-73. PMID: 19694823.

11. Cibert J, Garbit JL, Massoumi Mohajder R, Ogawa A, Gabrielli G. The use of intestinal grafts in urology. J urol Nephrol (Paris). 1968;7494):567-85. PMID: 5724597.

12. Jednak R. The evolution of bladder augmentation: from creating a reservoir to reconstituting na organ. Front Pediatr. 2014;2:10. PMID: 24575395.

13. Varghese F, Bukhari AB, Malhotra R, De A. IHC Profiler: an open source plugin for the quantitative evoluation and automated scoring of immunohistochemistry images of human tissue samples. PLos One. 2014;9(5):e96801. PMID: 24802416.

14. Gitlin JS, Wu Xen-Ru, Su Tung-Tien, Ritchey ML, Shapiro E. New concepts of histological changes in experimental augmentation cystoplasty: insights into the development of neoplastic transformation at the enterovesical and gastrovesical anastomosis. J Urol. 1999;162:1096-100. PMID: 10458439.

15. Ali-El-Dein B, El-Tabey N, Abdel-Latif M, Abdel-Rahim M, ElBahnasawy S. Late uro-ileal cancer after incorporation of ileum into the urinary tract. J Urol. 2002;167:84-7. PMID: 11743281.

16. Miranda EG, Bizerra MRS, Waisberg DR, Carnevale J, Silva JF, Waisberg J. Early morphological and histochemical alterations in rats subjected to ileocystoplasty. Acta Cir Bras. 2009;24(5):395-9. PMID: 19851693.

17. Castro Ma, Ferreira U, Martins MH, Stoppiglia RM, Netto Jr NR. Histological and histochemical changes of the intestinal mucosa at the urothelial-enteric anastomotic site. Int Braz J Urol. 2006;32:2227. PMID: 16650304.

18. Kalble T, Hofmann I, Riedmiller H, Vergho D. Tumor growth in urinary diversion: a multicenter analysis. Eur Urol. 2011;60:1081-6. PMID: 21802831.

19. Menezes HL, Jucá MJ, Gomes EGA, Nunes BGBBP, Costa HO, Matos D. Analysis of the immunohistochemical expressions of $\mathrm{p} 53$, bcl-2 and ki-67 in colorectal adenocarcinoma and correlations with the prognostic factors. Arq Gastroenterol. 2010;47(2):141-7. PMID: 20721457.

20. Davidsson T, Carlén B, Bak-Jensen E, Willén R, Mansson W. Morphologic changes in intestinal mucosa with urinary contact effects of urine or disuse? J Urol. 1996;156:226-32. PMID: 8648812.

21. Miranda EG, Nascimento VP, Waisberg DR, Sousa MWGS, Lima MFMB, Silva DS, Waisberg J. Inhltion anesthesia equipment for rats with provision of simultaneous anesthetic and oxygen. Acta Cir Bras. 2011;26(2):140-3. PMID: 21445478.

22. Di Cataldo S, Ficarra E, Acquaviva A, Macci E. Automated segmentation of tissue images for computerized IHC analysis. Comput Methods Programs Biomed. 2010;100(1):1-15. doi: 10.1016/j.cmpb.2010.02.002.

23. Brey EM, Lalani Z, Johnston C, Wong M, Mcintire LV, Duke PJ, Patrick CW Jr. Automated selection of DAB-labeled tissue for immunohistochemical quantification. J Histochem Cytochem. 2003;51(5):575-84. PMID: 12704205.

24. Castellan M, Gonsalbez R, Perez-Braufield M, Healey P, McDonald R, Labbie A, Lendvay T. Tumor in bladder reservoir after gastrocytoplasty. J Urol. 2007;178(4 Pt 2):1771-4. PMID: 17707009.

25. Botelho CHA, Magalhães AV, Mello PA, Schmitt FC, Casulari AA. Expression of P53 and C-erb B2 in growth hormone - and/ or prolactin- secreting pituitary adenomas. Arq Neuropsiquiatr. 2006;64(1):60-6. PMID: 16622555.

26. Dixon BP, Chun A, Henry J, Kim R, Bissler JJ. Increased cancer risk of augmentation cystoplasty: possible role for hyperosmolal 
Miranda EG et al.

environment on DNA demage recognition. Mutat Res. 2009;670(12):88-95. PMID: 19647003.

27. Dapena L, Dapena I, Regadera J, Silva-Mato A, González-Peramato P. Bladder autoaugmentation with protective autologous uterine flap. Experimental study in the rat. Int J Surg. 2013;11(3):270-4. PMID: 23385290.

\section{Correspondence:}

Edinaldo Gonçalves de Miranda

Rua Jaime da Botica, 3442

64050-040 Teresina - PI Brasil

Tel.: (55 86) $99497-3373$

edinaldomiranda@hotmail.com

Received: Sept 22, 2015

Review: Nov 18, 2015

Accepted: Dec 23, 2015

Conflict of interest: none

Financial source: Universidade Estadual do Piauí (FACIME/UESPI)

${ }^{1}$ Research performed at Department of Pediatric Surgery, Faculty of Medical Sciences, Universidade Estadual do Piauí (FACIME/UESPI) and Department of Surgery, Escola Paulista de Medicina (EPM), Universidade Federal de São Paulo (UNIFESP), Brazil. Part of Master degree thesis, Postgraduate Program in Interdisciplinary Surgical Science. Tutor: Jaques Waisberg. 